\title{
PERIPHERAL CHAMBER DEPTH IN SHALLOW ANTERIOR CHAMBER*
}

\author{
BY \\ RAGNAR TÖRNQUIST \\ From the Ophthalmic Clinic, University of Gothenburg, Sweden \\ Director: Prof. Bengt Rosengren
}

THE particular structure of the eye predisposing to primary acute (closedangle) glaucoma is a shallow anterior chamber, yet many eyes with a chamber depth of equal dimensions to those of glaucomatous eyes escape attacks of angle-closure. With the dark-room test no or only slight increase in pressure is generally obtained (Törnquist, 1958). Thus, presumably, an additional anatomical or functional factor is present in glaucomatous eyes but is absent in a normal eye with a shallow chamber.

Case reports wherein areas of thinned iris were observed indicate a higher pressure behind the iris than in the anterior chamber (Ulbrich, 1908; Heine, 1913; Urbanek, 1921; Miller, 1956). According to a theory developed by Curran (1920), Bänziger (1922), and Chandler (1952), a bulging of the iris occurs because of a relative hindrance of the aqueous humour between the iris and the lens ("relative pupillary block"). With a varying iris bombé, the chamber angle may be closed.

The width of the angle does not seem to be equal in different sections of the chamber (Barkan, 1938; Phillips, 1956b). The upper part is the more narrow, and this has been explained by the weight of the aqueous humour (Barkan) or by an uneven peripheral flattening of the cornea (Phillips). The upper half of the chamber has been observed by Heim (1941) to be smaller in volume than the lower half. In closed-angle glaucoma, gonio-synechiae tend to occur mainly in the upper part (Phillips 1956a).

Not only the axial chamber depth but also the form of the chamber thus seems to be of importance in the pathogenesis of closed-angle glaucoma. The purpose of this communication is to study the relative depth in different parts of the anterior chamber in a series of eyes with a shallow anterior chamber.

\section{Material}

A group of forty patients with closed-angle glaucoma (average age 61 years) and another group of 24 non-glaucomatous persons with a shallow anterior chamber (average age 52 years) were examined. The axial chamber depth measured by Stenström's apparatus is shown in Table I (overleaf). The examinations were performed when the intra-ocular pressure was normal. 
TABLE I

AXIAL CHAMBER DEPTH MEASURED BY STENSTRÖM'S INSTRUMENT

\begin{tabular}{|c|c|c|c|c|c|c|c|}
\hline & \multirow{2}{*}{ Eyes } & & & \multirow{2}{*}{ Number } & \multicolumn{3}{|c|}{ Chamber Depth (mm.) } \\
\hline & & & & & Lowest & Mean & Highest \\
\hline \multirow{2}{*}{ Glaucomatous } & Unoperated & .. & . & 49 & 1.33 & $1 \cdot 79$ & $2 \cdot 46$ \\
\hline & Operated & .. & . & 20 & $1 \cdot 25$ & $1 \cdot 65$ & $2 \cdot 50$ \\
\hline \multicolumn{2}{|c|}{ Non-glaucomatous } & .. & . & 48 & 1.43 & $2 \cdot 01$ & $2 \cdot 50$ \\
\hline
\end{tabular}

The mean values in a random series of non-glaucomatous persons (Törnquist, 1953) at the age of 50-60 years are: Males $2 \cdot 8-2 \cdot 7 \mathrm{~mm}$. Females $2 \cdot 7-2 \cdot 6 \mathrm{~mm}$.

\section{Methods}

The profile of the anterior eye segment was photographed and the relative depth in different parts of the chamber was determined from the pictures.

A Haag-Streit slit-lamp microscope with its standard source of light was used. Light from a very narrow vertical slit was projected along the visual axis of the eye, and the subject was requested to look right into the light. The beam was focused onto the anterior surface of the iris and the lens so that the pupil was divided into two halves by the image of the slit. The supporting arm of the microscope was fixed at an angle of 45 degrees to the right of the slit lamp. The image formed by the slit lamp was photographed with the camera (Alpa Reflex) fitted on the microscope. At least four pictures were taken of each eye, two of the central and upper sections, and two of the central and lower sections. The exposure was $1 / 25 \mathrm{sec}$. The film (Kodak Tri X) was underexposed, but by prolonging the development (Promicrol developer 16-18 min. at $20^{\circ} \mathrm{C}$.) good negatives were obtained. These were enlarged in copying so that the ultimate picture showed the chamber magnified ten times (Fig. 1, opposite).

By measuring the photographs the following proportions were calculated (Fig. 2, opposite). The axis of the eye was obtained by drawing a line perpendicular to the pupillary plane through the centre of the pupil. Then two lines were drawn parallel to the axis through the upper and lower part of the chamber at a given distance from the axis ( $a=33.5 \mathrm{~mm}$., corresponding to $3.35 \mathrm{~mm}$. in the eye). The apparent chamber depths $d_{s}, d$, and $d_{i}$ were measured to within 0.1 or $0.2 \mathrm{~mm}$. corresponding to chamber depths of 0.01 or $0.02 \mathrm{~mm}$.

The ratios $\frac{d_{s}}{d}$ and $\frac{d_{i}}{d}$ were then calculated from these measurements.

Errors of the Method.-As the series only includes individuals with a shallow anterior chamber, the cornea was generally reproduced with satisfactory sharpness although the light was focused on the iris. In a few cases the dispersion of light into the iris was so great that it was impossible to make any measurements.

It seems probable that accommodation was absent or insignificant during the procedure. The majority of the examined persons were presbyopes.

On account of the refraction of light at the corneal surface the apparent chamber depths are smaller than the real ones. As regards axial depth this reduction can easily be estimated (Törnquist, 1953), and as the radius of curvature of the corneal surface increases the apparent chamber depth decreases. 


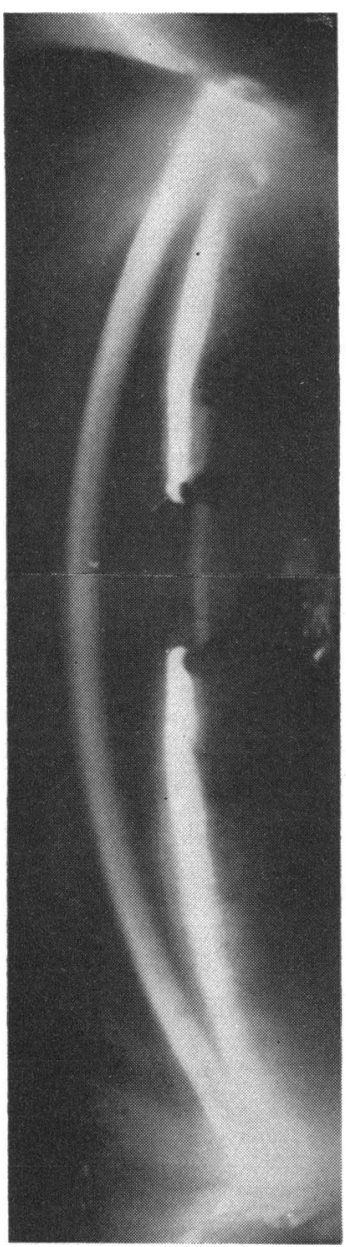

FIG. 1.-Example of a slit-lamp photograph $\times 10$.

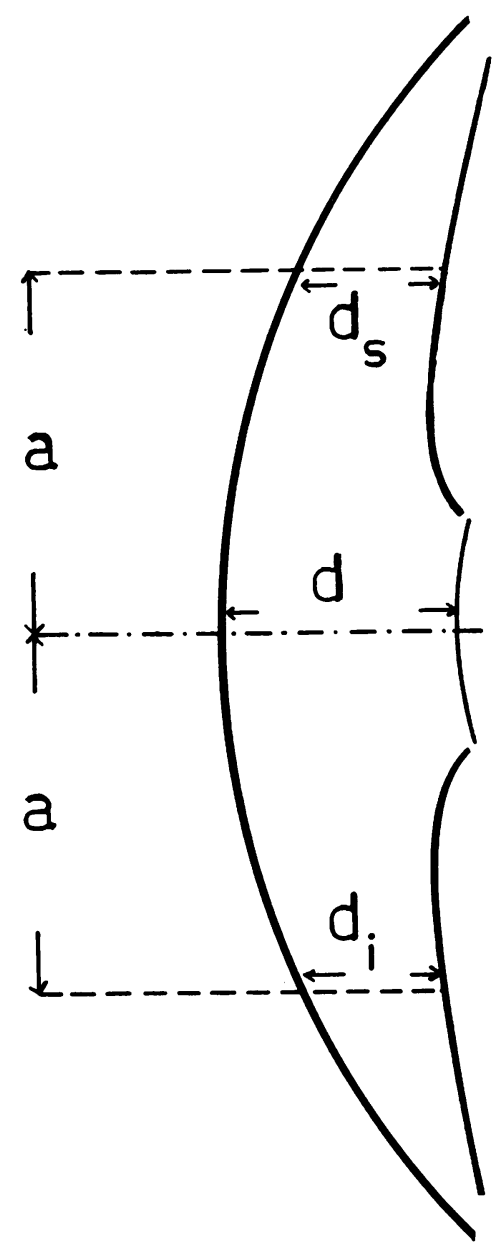

FIG. 2.-Diagram for calculating chamber depths.

(a) Distance from axis (constantly $33.5 \mathrm{~mm}$. on the photographs, representing $3.35 \mathrm{~mm}$. in the eye).

(d) Apparent axial chamber depth.

$\left(d_{s}\right)$ Apparent peripheral depth in upper part of chamber.

$\left(d_{i}\right)$ Apparent peripheral depth in lower part of chamber.

To measure the effect of the refraction of light in the non-axial region the following experiment was made. A contact glass with a radius of curvature of $7.7 \mathrm{~mm}$. in the corneal part, and $13 \mathrm{~mm}$. in the scleral part, and a corneal diameter of $12 \mathrm{~mm}$., was used. The corneal part was filled with normal saline solution. A spherical steel ball of radius $13 \mathrm{~mm}$. was placed in the scleral part. Thus an artificial chamber limited by two spherical surfaces with known radii was produced, and this was photographed in the same way as the eyes. The apparent chamber depths measured on the photographs were compared with the calculated actual 
distances. The experiment showed that the apparent depths were 25 per cent. smaller than the real depths, and that there was no significant difference as regards the reduction between the axial and the peripheral distances. Thus, the ratio between the two distances was the same.

The corneal surface is spherical only within a central area, however, and it flattens out in the periphery, this flattening being most obvious upwards (Berg, 1931). The radius of curvature may therefore be expected to be at its smallest where the distance $d$ is measured, greater at $d_{i}$, and greatest at $d_{s}$. The reduction of the real distances may be comparatively greater at the periphery and especially at $d_{s}$. This variation cannot be estimated with exactitude, but is probably small. In a shallow chamber with an axial depth of about $2 \mathrm{~mm}$., the conceivable variation of the curvature implies that the apparent peripheral depth is not more than 0.01 or $0.02 \mathrm{~mm}$. less than if the radius had been constant. Thus, this systematic error is probably smaller than the error of measurement.

The random error of the method is probably comparatively small. After a short interval a second examination of five normal eyes was performed. The difference between the ratios varied between 0 and 0.06 and the mean was 0.03 .

\section{Results}

As is shown in Table II the peripheral chamber depth in non-glaucomatous eyes measured by this method is 38 per cent. of the axial depth in the upper section of the chamber and 47 per cent. in its lower section. A significant difference is also found in unoperated glaucomatous eyes.

TABLE II

RELATIONSHIP BETWEEN PERIPHERAL AND AXIAL CHAMBER DEPTH IN UPPER $\left(\frac{d_{s}}{d}\right)$ AND LOWER $\left(\frac{d_{i}}{d}\right)$ PARTS OF CHAMBER

\begin{tabular}{|c|c|c|c|c|}
\hline \multicolumn{2}{|l|}{ Eyes } & $\frac{d s}{d}$ & $\frac{d_{i}}{d}$ & Difference \\
\hline \multirow[b]{2}{*}{ Unoperated Glaucomatous } & No. & 49 & 49 & \multirow[b]{2}{*}{$0.11 \pm 0.014$} \\
\hline & $\underset{s}{m \pm e_{m}}$ & $\begin{array}{c}0.27 \pm 0.010 \\
0.07\end{array}$ & $\begin{array}{c}0.38 \pm 0.010 \\
0.07\end{array}$ & \\
\hline \multirow{2}{*}{$\begin{array}{l}\text { Non-glaucomatous with } \\
\text { Shallow Anterior Chamber }\end{array}$} & No. & 46 & 48 & \multirow[b]{2}{*}{$0.09 \pm 0.018$} \\
\hline & $\underset{s}{m \pm e_{m}}$ & $\begin{array}{c}0.38 \pm 0.013 \\
0.09\end{array}$ & $\begin{array}{c}0.47 \pm 0.012 \\
0.08\end{array}$ & \\
\hline \multicolumn{2}{|l|}{ Difference } & $0 \cdot 11 \pm 0 \cdot 016$ & $0.09 \pm 0.016$ & \\
\hline
\end{tabular}

In non-glaucomatous eyes the ratio between the peripheral and the axial chamber is found to be less when the chamber is very shallow $(<2.0 \mathrm{~mm}$.) than when it is moderately shallow $(2 \cdot 0-2 \cdot 5 \mathrm{~mm}$.). The difference is significant (Table III, opposite). 
TABLE III

RELATIONSHIP BETWEEN PERIPHERAL AND AXIAL CHAMBER DEPTH IN UPPER $\left(\frac{d_{s}}{d}\right)$ AND LOWER $\left(\frac{d_{i}}{d}\right)$ PARTS OF CHAMBER

Non-glaucomatous eyes with different chamber depths

\begin{tabular}{|c|c|c|c|}
\hline \multicolumn{2}{|c|}{ Chamber Depth (Stenström) } & $\frac{d s}{d}$ & $\frac{d_{i}}{d}$ \\
\hline \multirow[b]{2}{*}{$1 \cdot 40-1 \cdot 99$} & No. & 24 & 26 \\
\hline & $m \underset{s}{m} e_{m}$ & $\begin{array}{c}0.31 \pm 0.011 \\
0.06\end{array}$ & $\begin{array}{c}0.42 \pm 0.013 \\
0.06\end{array}$ \\
\hline \multirow[b]{2}{*}{$2 \cdot 00-2 \cdot 50$} & No. & 22 & 22 \\
\hline & $\underset{s}{m \pm e_{m}}$ & $\begin{array}{c}0.42 \pm 0.021 \\
0 \cdot 10\end{array}$ & $\begin{array}{c}0.53=0.014 \\
0.07\end{array}$ \\
\hline \multicolumn{2}{|l|}{ Difference } & $0 \cdot 11=0.024$ & $0.11 \pm 0.019$ \\
\hline
\end{tabular}

In comparing non-glaucomatous and unoperated glaucomatous eyes, it is found that in the latter the ratios are less and the differences between the groups are significant (Table II).

In six cases photographs were taken before and after peripheral iridectomy in the upper chamber angle.

Table IV shows that the ratio $\frac{d_{i}}{d}$ clearly increases.

TABLE IV

RELATIONSHIP BETWEEN PERIPHERAL AND AXIAL CHAMBER DEPTH IN LOWER PART OF CHAMBER $\left(\frac{d_{i}}{d}\right)$ BEFORE AND AFTER PERIPHERAL IRIDECTOMY

\begin{tabular}{|c|c|c|c|c|c|c|}
\hline \multirow{2}{*}{$\begin{array}{l}\text { Case } \\
\text { No. }\end{array}$} & \multirow{2}{*}{$\begin{array}{c}\text { Age } \\
\text { (yrs) }\end{array}$} & \multirow{2}{*}{ Sex } & \multirow{2}{*}{ Eye } & & $\frac{d_{i}}{d}$ & \\
\hline & & & & Before Operation & After Operation & $\begin{array}{l}\text { Difference } \\
\text { (II)-(I) }\end{array}$ \\
\hline 1 & 50 & $\mathrm{M}$ & $\mathrm{R}$ & 0.45 & 0.53 & 0.08 \\
\hline 2 & 46 & $\mathrm{~F}$ & $\begin{array}{l}\mathrm{R} \\
\mathrm{L}\end{array}$ & $\begin{array}{l}0 \cdot 39 \\
0 \cdot 48\end{array}$ & $\begin{array}{l}0.67 \\
0.57\end{array}$ & $\begin{array}{l}0 \cdot 28 \\
0 \cdot 09\end{array}$ \\
\hline 3 & 48 & $\mathrm{M}$ & $\mathrm{R}$ & $0 \cdot 36$ & 0.46 & $0 \cdot 10$ \\
\hline 4 & 59 & $\mathrm{~F}$ & $\mathrm{R}$ & 0.49 & 0.59 & $0 \cdot 10$ \\
\hline 5 & 47 & $\mathrm{~F}$ & $\mathrm{~L}$ & 0.36 & 0.55 & $0 \cdot 19$ \\
\hline
\end{tabular}


In the whole series of glaucomatous eyes the same ratio is greater in the operated than in the unoperated eyes and the difference is significant (Table V). The ratios of the eyes operated upon seem to be on an average even higher than those of non-glaucomatous eyes.

TABLE V

RELATIONSHIP BETWEEN PERIPHERAL AND AXIAL CHAMBER DEPTH IN LOWER PART OF CHAMBER $\left(\frac{d}{d}\right)$ AFTER PERIPHERAL IRIDECTOMY, IN UNOPERATED GLAUCOMATOUS EYES, AND IN NON-GLAUCOMATOUS EYES WITH SHALLOW ANTERIOR CHAMBER

\begin{tabular}{|c|c|c|c|c|}
\hline \multicolumn{3}{|c|}{ Eyes } & $\underline{d_{i}}$ & Difference \\
\hline \multirow{4}{*}{ Glaucomatous } & \multirow{2}{*}{ Unoperated } & No. & 49 & \multirow{6}{*}{$0.14 \pm 0.021$} \\
\hline & & $\underset{s}{m \pm e_{m}}$ & $\begin{array}{c}0.38 \pm 0.010 \\
0.07\end{array}$ & \\
\hline & & No. & 20 & \\
\hline & Operated & $\underset{s}{m \pm e_{m}}$ & $\begin{array}{c}0.52 \pm 0.019 \\
0.09\end{array}$ & \\
\hline \multirow{2}{*}{\multicolumn{2}{|c|}{$\begin{array}{l}\text { Non-Glaucomatous with } \\
\text { Shallow Anterior Chamber }\end{array}$}} & No. & 48 & \\
\hline & & $\begin{array}{c}m \pm e_{m} \\
s\end{array}$ & $\begin{array}{c}0.47 \pm 0.012 \\
0.08\end{array}$ & \\
\hline
\end{tabular}

$m$ arithmetic mean

$e_{m}$ standard error of the mean

$s$ standard deviation

\section{Discussion}

There is a reduction of the real depth caused by refraction. On account of a greater corneal flattening upwards there is a difference in reduction between the upper and lower parts. This difference is however very small. The significance of the measured difference probably is not influenced by this error. The result supports previous observations by Barkan and by Phillips and is in accordance with the observation of Heim (1941) that the upper part of the chamber has a smaller volume than the lower. A study of the photographs indicates that the surface of the iris is probably slightly more protruding upwards.

In eyes with closed-angle glaucoma, the peripheral chamber depth was comparatively less than in non-glaucomatous eyes with the same shallowness of the chamber. As glaucomatous eyes on an average probably have a smaller corneal diameter (Priestley Smith, 1890; Barkan, 1954b) and a smaller radius of corneal curvature (Törnquist, 1957), consideration should be taken to which extent these factors can have contributed to the present difference. 
The distance between the upper and lower points of the chamber angle was estimated from the photographs. On the basis of the means in the group of unoperated glaucomatous eyes and the group of non-glaucomatous eyes, and the corresponding means of the radius of the corneal curvature, an estimation was made of the effect on the peripheral chamber depth. Only a small decrease ( 5 per cent.) in the glaucomatous eyes was obtained.

It is therefore probable that the difference in the relative peripheral chamber depth between the glaucomatous and the non-glaucomatous eyes is due to an increased convexity of the surface of the iris.

In an earlier investigation, no significant change of the axial chamber depth after operation was found (Törnquist; 1956). On the other hand, in the present series of eyes operated upon (peripheral iridectomy) an obvious increase in the peripheral chamber depth was demonstrable. This change speaks in favour of an iris bombe in unoperated acute glaucoma, i.e. that the iris bulges because of a higher pressure in the posterior chamber.

In the non-glaucomatous eyes with a shallow anterior chamber, the ratio between the peripheral and the axial chamber depth is probably somewhat less than in the glaucomatous eyes operated upon. Should this be confirmed in a larger series a certain degree of iris bombé would also be established in non-glaucomatous eyes with a shallow chamber. A comparison between eyes with a moderately shallow and excessively shallow chamber shows that the bulging of iris increases with decreasing chamber depth.

The results indicate that the shallow anterior chamber is often associated with a relative blocking of aqueous humour between the lens and the iris causing an iris bombé. This was also suggested by Barkan (1954a). The reason for this bulging being more obvious in certain eyes-those which develop attacks of angle-closure - cannot be given. Possibly there are variations in the thickness or the resistance of the iris.

\section{Summary}

On slit-lamp photographs of the anterior chamber, the apparent chamber depths at the axis and peripherally at a fixed distance from the axis were measured. Forty patients with acute closed-angle glaucoma and 24 nonglaucomatous individuals with a shallow anterior chamber were examined.

The ratio between the peripheral and axial depth was significantly smaller in the upper part than in the lower part of the chamber. In eyes with closedangle glaucoma the same ratios were smaller than in the non-glaucomatous eyes, and the differences were significant. After a peripheral iridectomy, however, the values were equal to or slightly larger than those of nonglaucomatous eyes. In the latter group a smaller ratio was found with smaller chamber depth. The cause of these findings was discussed.

This study was supported by a grant from the Swedish Medical Research Council. 


\section{REFERENCES}

Barkan, O. (1938). Amer. J. Ophthal., 21, 1099. (1954a). Ibid., 37, 332.

(1954b). Ibid., 37, 724

BERG, F. (1931). Acta ophthal. (Kbh.), 9, 53.

BAENZIGER, T. (1922). Ber. dtsch. ophthal. Ges., 43, 43.

Chandler, P. A. (1952). A.M.A. Arch. Ophthal., 47, 695.

Curran, E. J. (1920). Arch. Ophthal. (Chicago), 49, 131.

HeIM, M. (1941). Ophthalmologica (Basel), 102, 193.

HEINE (1913). Ber. dtsch. ophthal. Ges., 39, 398.

Miller, S. J. H. (1956). Brit. J. Ophthal., 40, 248.

Phillips, C. I. (1956a). Ibid., 40, 129. (1956b). Ibid., 40, 136.

SMITH, P. (1890). Trans. ophthal. Soc. U.K., 10, 68.

TÖRNQUisT, R. (1953). Acta ophthal. (Kbh.), Suppl. 39. (1956). Brit. J. Ophthal., 40, 421. (1957). Ibid., 41, 421.

(1958). Acta ophthal. (Kbh.), 36, 664.

Ulbrich, H. (1908). Arch. Augenheilk., 60, 283.

URBANEK, J. (1922). Verh. ophthal. Ges. Wien, p. 133. 